\title{
An Empirical Study on the Impact of Pre-interpreting Preparation on Business Interpreting under Gile's Efforts Model
}

\author{
Xiaoli Song \\ Department of Foreign Languages, North China Electric Power University, Beijing, China \\ Mingzhu Tang \\ School of International Studies, University of International Business and Economics, Beijing, China
}

\begin{abstract}
With Gile's Efforts Model as the theoretical foundation, this study aims at analyzing the effect of pre-interpreting preparation on business interpreting between English and Chinese, particularly focusing on the following two questions: 1. Does pre-interpreting preparation affect the quality of students' business interpreting output? If so, how it affects the various factors of interpreting output quality? 2. Will the pre-interpreting effect change with the different language levels? To answer these two questions, we carried out an experimental study by testing sample students' interpretation on a selected business interview without any preparation and with adequate preparation respectively. With the data collected, we made both quantitative and qualitative analysis. Based on the analysis, the following conclusions are reached: First, pre-interpreting preparation has a positive effect on the overall quality of business interpreting output. Second, in business scenarios, pre-interpreting preparation have different degrees of impact on the factors of interpretation quality. Specifically, it has a relatively large impact on the accuracy of terminology and the logical coherence of the target-language speech, while exerting a minimal impact on the voice quality. Third, pre-interpreting preparation has a greater influence on the interpreting output of the intermediate language level group than it has on the advanced language level group. It is hoped that this study could provide some new perspectives and offer some help to the teaching of business English interpreting.
\end{abstract}

Index Terms - Gile's efforts model, pre-interpreting preparation, interpretation quality

\section{INTRODUCTION}

With the ever-increasing economic globalization, communication between business people from different language background has become closer than ever before. Consequently, the demand for business interpreting services is also increasing, which has been attracting more and more interpreters to join in. However, since interpreting is an instant, dynamic and complex cross-cultural communication behavior (Wang Jinbo \& Wang Yan, 2006), and it involves professional knowledge of different business fields, the number of qualified interpreters in the industry is far from enough. There is still a huge gap in the demand and supply of high-end interpreting talents. Under such circumstances, many translating and interpreting departments of higher education institutions in China offer business interpreting courses.

Relevant research in cognitive psychology shows that human brain's capacity to process information is limited. When multiple tasks are carried out simultaneously, we must allocate our attention accordingly. If one's total capacity is less than required, or the allocation of capacity is not appropriate, there will be a situation of cognitive overload and the task will not be able to proceed smoothly. Based on this theory, Gile (1995) proposes a cognitive load model in interpreting process. According to the model, consecutive interpreting (CI) can be modeled as a process consisting of four "efforts", namely "listening and analysis effort", "short-term memory effort", "speech production effort", and "coordination effort". In order for interpreting to proceed smoothly, the cognitive load of interpreting should be less than the total available processing capacity of the interpreter. In addition, Gile also puts forward that an interpreter's listening comprehension capacity depends on one's language knowledge, extra-language knowledge and analysis. Language knowledge refers to the bilingual capacity of interpreters, such as listening, speaking, reading, and writing. Extra-language knowledge includes common knowledge, professional knowledge, context awareness and cross-cultural awareness etc. (Gao Weihong, Li Jinshong, 2013). Both language knowledge and extra-language knowledge require long-term practice and accumulation on the interpreters' part. But some extra-language knowledge, such as subject knowledge, background knowledge, terms, access to source speech, information about speaker, etc., can also be obtained through short-term preparation. And such a preparing process can be regarded as pre-interpreting preparation.

Whether pre-interpreting preparation can improve the quality of interpreting output has been answered in the affirmative by some scholars (Zhang Jiliang, 2003; Liu Heping, 2007), but till now, few studies use Gile's Effort Model to conduct experimental research in discussing the impact of pre-interpreting preparation on the specific factors of 
quality of interpretation in business context. Therefore, this study attempts to use Gile's Efforts Model as theoretical framework to explore the influence of pre-interpreting preparation on the different factors of interpreting quality, so as to offer some practical suggestions on the teaching of business interpreting.

\section{PRE-INTERPRETING PREPARATION}

Seleskovitch (1978) believes that complete and accurate interpretation depends largely on the interpreter's grasp of the subject knowledge and context. In many interpreting cases, the subject knowledge of interpreting is new to the interpreter, which establishes the necessity of pre-interpreting preparation. Gile (2009) claims that in many occasions where interpretation services are offered, the interpreter is not a professional in that field, so preparation before interpretation is of great importance. Stoll (2009) holds that pre-interpreting preparation can effectively reduce the cognitive load and improve interpreting output. In order to explore the relationship between pre-interpreting preparation and interpreting output quality, Liu Heping (2007) selected 20 undergraduates and 6 graduate students to conduct an interpreting experiment. The results show that pre-interpreting preparation improved the interpreting output greatly. Zhang Jiliang (2003) believes adequate preparation is very important for interpreters. Even senior interpreters with adequate pre-interpreting preparations will have a better interpreting output. Xu Ran (2018) proposes that interpreters' access to subject knowledge is mainly achieved through terms. He finds that most student interpreters can quickly improve terminology accuracy in interpretation with the help of Sketch Engine platform (a corpus assisting tool). Zhong Huimin (2016) also puts forward that subject familiarity has significantly improved the accuracy of terms and core concept in interpreting process.

Literature shows that pre-interpreting preparation has positive influence on the interpreting output. Then, on what aspects shall interpreters focus on when doing preparation? Zhang Jiliang (2003) suggests that pre-interpreting preparation should include terminology, subject knowledge, information about speakers and listeners, and psychological preparation. Interpreters are also expected to familiarize themselves with interpretation tools, interpretation venues and equipment. According to the preparation time, preparation for interpretation can be divided into long-term preparation and short-term preparation. Long-term preparation includes listening practice, learning of knowledge in various fields, and accumulation of interpretation skills from long-time perspective, while short-term preparation mainly includes preparation on subject knowledge, terminology, speakers and target audience, interpretation equipment, etc. (Li Wei ,2009). Both long-term preparation and short-term preparation are important to the interpreting performance. It is worth noting that this study focuses on short-term preparation. In the interpretation experiment, information on the subject knowledge, professional terminology, speaker and target listener, and interpretation tools are provided to the tested student interpreters to prepare before doing business interpreting test.

\section{GILE'S EFFORTS MODEL}

\section{A. The Development of Efforts Model}

Interpreting process includes a series of cognitive activities, such as listening, memorizing, note-reading, analyzing and speech production. Therefore, interpreting research involves many concepts in the fields of cognitive psychology and psycholinguistics, like attention and information processing capacity. These concepts have become an important theoretical basis for interpreting research. Since the 1970s, western scholars in interpreting field have begun to study interpreting from the cognitive perspective, especially the information processing model in the interpreting process. Gerver (1976) proposes that interpreting is a complex information processing process, including information acquisition, storage, extraction, transformation and expression. From the perspective of cognitive linguistics, Moser defines interpreting as "a multi-process activity composed of information analysis, storage mechanism, transformation, expression and expression supervision mechanism" (Moser, 1997, p.177). Lambert (1989) believes that the information processing mode in interpreting needs a special mechanism to store and process information simultaneously.

In the 1970s, Daniel Gile, a well-known interpreting researcher and professor at Ecole Supérieur d'Interprètes et de Traducteur of Université Sorbonne Nouvelle-Paris 3 (ESIT) put forward the Effort Models for Simultaneous Interpreting (SI) and Consecutive Interpreting (CI) on the basis of cognitive psychology. After continuous study and improvement, the model gradually developed and became matured. According to Gile, the original purpose of the model is not to describe the interpreting process, but to analyze some of the problems frequently encountered in interpreting and the solutions to them. The Effort model has an important influence on the subsequent research in the interpreting field. It is worth noting that this study focuses on the efforts model for CI.

\section{B. Two Phases of Efforts Model for CI}

Phase 1: the listening and note-taking phase. In this phrase, the following tasks are included:

Listening and analysis (L) is the first step in the interpreting process. If there is any difficulty in listening comprehension, the subsequent short-term memory and interpreting output will be inevitably influenced. In most cases, if the source language is not the native language of the interpreter, the chances of losing or misunderstanding important information will be greater, resulting in a decline in interpretation quality. In addition, speakers from different countries, even if they use the same language, will have differences in pronunciation, intonation and lexical choice, which will 
also affect listening comprehension, then the interpreting effect. Gile proposes "comprehension=knowledge for the language + extra-linguistic knowledge + analysis" (Gile, 1995, p.80). Therefore, interpreters should improve their bilingual ability and expand their knowledge in various fields, so as to reduce the listening comprehension load in interpreting process.

Note-taking $(\mathrm{N})$. Notes can help interpreters recall what they have just heard and guide the interpreter to complete the memory activity. However, note-taking can only play an auxiliary role in short-memory activity and cannot replace brain memory. The interpreter should know how much notes are appropriate because too few notes cannot help the interpreter to complete the memory while too many notes take too much attention and inevitably affect other tasks in the interpreting process. Therefore, the interpreter should develop his/her own note-taking strategy in practice, striving to reduce the time and load of taking notes.

Short-term memory (M). Short-term memory is crucial in the entire communication process. Whether the source speech information can be effectively stored in the interpreter's mind is the key to achieving high-quality interpreting output. Factors like strong accent of the speaker, the heavy information density of the speech, the unusual language structure and unfair topic of the source speech will increase the short-term memory load, thus affecting the interpreting output negatively.

Coordination (C). In the process of CI, listening and analyzing, note-taking, memorizing and speech production need to be carried out simultaneously. However, the interpreter's cognitive supply is limited, which requires the interpreter to allocate his/her attention appropriately according to their capacity and actual interpreting situation, so as to maximize their cognitive ability and successfully complete the interpreting task. At the same time, the coordination itself also requires the effort of the interpreter.

Interpreting in the first phase is described by Gile with this equation: $C I=L+N+M+C$ (Gile, 1995).

Phase 2: the speech production phase. In this phrase, the following tasks are included:

Remembering (Rem). Remembering at this stage is to recall the successive parts of the original speech from long-term memory to form a logical and continuous language segment. Therefore, high-quality interpreting is by no means a mechanical translation of the source language word by word, but on the basis of correct and complete understanding the source speech.

Note-Reading (Read). Reading of notes refers to the mental processing of the notes taken in the first stage, with the purpose of stimulating the memory and helping the interpreter to form a complete language segment right before the target language production.

Production (P). Production is the final step in the interpreting process, which means that the interpreter delivers the information expressed by the speaker in the target language.

The second stage is described by Gile with this equation: $C I=\operatorname{Rem}+\operatorname{Read}+\mathrm{P}$ (Gile, 1995).

\section{Operational Requirements}

According to Gile(1995), operational processing capacity requirements during CI can be represented as follows:

$\mathrm{TR}=\mathrm{LR}+\mathrm{NR}+\mathrm{MR}+\mathrm{CR}$

TR represents Total processing capacity requirements

LR represents capacity requirements for $\mathrm{L}$

$\mathrm{NR}$ represents capacity requirements for $\mathrm{N}$

MR represents capacity requirements for $\mathrm{M}$

$\mathrm{CR}$ represents capacity requirements for $\mathrm{C}$

$\mathrm{R}$ represents requirements

According to this equation, the total processing capacity required for interpreting activities is equal to the sum of the processing capacity required for each activity. And only when the following conditions are met can the interpreting activities proceed smoothly.

$\mathrm{TR}<\mathrm{AR}$ Total processing capacity requirements < Total available capacity

LR $<$ LA Capacity requirements for $\mathrm{L}<$ capacity available for $\mathrm{L}$

$\mathrm{NR}<\mathrm{NA}$ Capacity requirements for $\mathrm{N}<$ capacity available for $\mathrm{N}$

$\mathrm{MR}<\mathrm{MA}$ Capacity requirements for $\mathrm{M}<$ capacity available for $\mathrm{M}$

$\mathrm{CR}<\mathrm{CA}$ represents capacity requirements for $\mathrm{C}<$ represents capacity available for $\mathrm{C}$

A represents available

These inequalities mean that the total capacity requirements should not exceed the interpreter's total available processing capacity. If this condition is not met, a situation of saturation arises. Another condition is that processing capacity available for each Effort should be sufficient to complete the task it is engaged in.

\section{GILE’S EFFORT MODEL AND PRE-INTERPRETING PREPARATION}

How to combine the Effort model with pre-interpreting preparation to improve the interpreting output has been studied by scholars at home and abroad. Cao Chengbi (2008) applies Efforts model and relevance theory to explore the relationship between pre-interpreting preparation and prediction strategy in simultaneous interpreting and proves that preparation has a positive impact on the prediction strategy. Based on Gile's efforts model, Shen Ying (2012) studies 
how pre-interpreting preparation, sight interpretation and on-site reading enhanced simultaneous interpreting. Tan Yanping (2009) proposes that the preparation of subject knowledge helps to improve the interpreter's ability to understand, short-term memory, and note-taking efficiency, thereby enhance the quality of interpreting output. Based on Efforts Model, Sun Mu (2017) makes a case study with his interpreting project to explain how pre-interpreting preparation helps his performance in the interpreting project.

Previous studies have shown that pre-interpreting preparation can improve the quality of interpreting. However, few studies have explored to what extent it affects the specific factors of the quality of business interpreting output from an empirical point of view and what practical significance does this have for business interpreting teaching. These issues will be the focus in our study. Moreover, as we all know, a typical interpreting class is composed of students at different language levels. Therefore, in order to offer more applicable suggestions on business interpreting teaching, we also want to know whether the effects of preparations on interpreting output change with the different language levels. Therefore, the main questions we are trying to answer through this study are as follows:

1. Does pre-interpreting preparation affect the quality of students' business interpreting output? If so, how it affects the various factors of interpreting output quality?

2. Will the pre-interpreting effect change with the different language levels?

\section{RESEARCH DESIGN}

\section{A. Tests and Testing Materials}

The tested students of this experimental study are senior students majoring in English at a Chinese university. They have taken comprehensive interpretation course for a year. We selected 36 students and divided them into advanced level group and intermediate level group based on their language ability. Those whose final score for the course "Comprehensive Interpretation" is between 85-95 belong to advanced level group, while intermediate level group includes students whose final score for this course is between 75-85. Among a total of 36 subjects were tested, 18 are in the advanced level group and 18 in the intermediate level group.

The testing material in the experiment is a typical business interpreting material-- an Interview with the Vice Governor of the People's Bank of China on issues related to the establishment of the Shanghai Headquarters by the People's Bank of China. The questions of the interview are in English, and the answers are in Chinese. The tested students are required to do interpretation from Chinese into English or vice versa. This material is selected from the Business Interpretation Unit of A Foundation Coursebook of Interpreting Between English and Chinese written by a well-known Chinese Professor in interpretation field (Zhong Weihe) and published by Higher Education Press in China. We use the recorded audio of the interview attached to the textbook as our source speech. In order to meet the experimental requirements, the test materials are divided into two parts. Part I is for test 1 (interpretation without preparation), and Part II is for test 2(interpretation with preparation). Since the two parts are about the same topic in the same interview, the difficulty of the two parts of the material is considered to be equivalent.

TABLE I.

COMPARISON OF TWO PARTS OF INTERPRETING MATERIALS

\begin{tabular}{|l|l|l|}
\hline Comparison factors & Part I & Part II \\
\hline Chinese characters & 525 & 541 \\
\hline English words & 185 & 196 \\
\hline Audio length & 3 ' $48^{\prime \prime}$ & 4 '05' \\
\hline Number of terms & 14 & 16 \\
\hline Long sentences in English & 4 & 5 \\
\hline Long sentences in Chinese & 7 & 7 \\
\hline Clarity of the source speech & clear & clear \\
\hline \multicolumn{2}{r}{ Lote: Long sentence in English refers to sentence with 20 or more words. } \\
\hline
\end{tabular}

\section{B. Experimental Procedure}

Due to the COVID-19 epidemic, the experiment was conducted on line. This experiment included two tests, namely test 1 and test 2 . Test 1 was to test students' interpretation without any preparation, which used Part 1 of the testing material. Test 2 was to test students' interpretation with adequate preparation, which used Part 2 of the testing material. The two tests were conducted within one week. Before Test 1, the students were asked to fill out a questionnaire about their listening habits, prior knowledge in finance field, psychological state about the interpreting test. Afterwards, the audio of Part 1 was sent to the students. There was a pause of 30 seconds between segments for the students to interpret. The tested students were required to record their interpreting with the help of some apps, which didn't pose any burden in the process of interpreting. When the interpreting was finished, the tested students were asked to send their recorded interpretation to the researchers immediately, without any edition. After that, the students needed to fill out a 
post-interpreting questionnaire about their performance in the unprepared interpreting test.

To avoid fatigue and strong test effects, test 2 was conducted five days later. For test 2, we carefully selected some materials for the students to prepare before interpreting. These materials offered information on the background of the interview, subject relevant knowledge, professional terminology and interpreting tools. The background interview part provided detailed information about the interviewer and the interviewee. The background knowledge part comprised of four Chinese-English bilingual passages, respectively introducing PBC Shanghai headquarter, American Central Banking System, PBC's role in China's Banking System and financial market, and major functions of PBC. The professional terminology part included 26 relevant terms. Considering that there are 10 pages of preparation materials and the students basically had no professional knowledge in the financial field, the students were given three days to read the preparation materials intensively to have a full understanding of the material. Then we had test 2 . The interpreting procedure and requirements were the same with that of test 1 . After the test, students were invited to fill out a post-interpreting questionnaire and write a personal log about the experiment, focusing on comparing their performance in test 1 and test 2.

\section{Grading and Data Analysis Methods}

When grading, we referred to the quality factors of interpreting output summarized in the study of Kurz (2001, 2002). Taking the features of business interpreting and the goal of this study into consideration, we graded the students interpreting output in both test 1 and test 2 according to the following factors: information integrity (50\%), terminology $(10 \%)$, fluency $(15 \%)$, logical coherence $(10 \%)$, grammatical correctness $(10 \%)$, and voice $(5 \%)$. In order to reduce the subjectivity in grading, we invited two graders to do the grading task. One was a vice-professor who has been teaching interpreting course for 10 years, and the other one was a senior interpreter with 7 years of interpreting experience in business field. To make sure the grading was not influenced by the experiment, the graders were not informed about anything of the experiment and the purpose of the grading.

In terms of data analysis, we adopted both quantitative and qualitative methods. The students' grades on each factor of the interpreting quality for both test 1 and test 2 were used for quantitative analysis with the help of SPSS and Stata. And the information collected in the questionnaire survey and log was used for qualitative analysis.

\section{RESULTS}

Altogether, we received a total of 72 groups of data, 36 for test 1 (unprepared interpreting test), 36 for test 2 (prepared interpreting test). Each group of data includes six scores, namely total score, score on information integrity, score on terminology, score on voice, score on grammatical correctness, score on coherence and score on fluency. In order to understand whether pre-interpreting preparation affects the quality of interpreting, the SPSS inter-subject effect test was conducted to obtain the following results.

TABLE II.

THE INFLUENCE OF PRE-INTERPRETING PREPARATION ON VARIOUS FACTORS OF INTERPRETATION QUALITY

\begin{tabular}{lllllllll}
\hline \multicolumn{1}{c}{ Source } & SS & DF & F & Sig. & \multicolumn{2}{c}{ Remaining } & \multicolumn{3}{c}{ Total } \\
\hline TS & 1250.00 & 1 & 29.78 & .000 & 2937.78 & 70 & 4187.78 & 71 \\
II & 260.68 & 1 & 26.02 & .000 & 701.19 & 70 & 961.88 & 71 \\
T & 68.06 & 1 & 64.62 & .000 & 73.72 & 70 & 141.78 & 71 \\
V & 1.13 & 1 & 5.30 & .024 & 14.86 & 70 & 15.99 & 71 \\
GC & 7.35 & 1 & 13.35 & .000 & 38.53 & 70 & 45.88 & 71 \\
LC & 12.50 & 1 & 19.84 & .000 & 44.11 & 70 & 56.61 & 71 \\
Fl & 13.35 & 1 & 8.38 & .005 & 111.53 & 70 & 124.88 & 71 \\
\hline
\end{tabular}

Confidence Interval $(\mathrm{CI})=99 \%$

Note: TS=Total Score, II=Information Integrity, T=Terminology, V=Voice, GC = Grammatical Correctness, LC = Logical Coherence, Fl =Fluency. Total Score $=$ Information Integrity $* 50 \%+$ Terminology*10\% + Fluency*15\% + Coherence*10\% + Grammatical Correctness $* 10 \%+$ Voice $* 5 \%$.

From the significance level of TS (total score), it can be seen that whether there is preparation before interpreting has a significant effect on the overall quality of interpreting output. From the value of Sig of F, it can be concluded that the preparation before interpreting has significant effect on the Factors of II (information integrity), T (terminology), GC (grammatical correctness), and LC (logical coherence) and Fl (fluency). The table also shows that the Sig of F of V (voice) $=0.024>0.01$, in the case of $\mathrm{CI}=99 \%$, which means that preparation does not have significant effect on the voice.

Then, we used Stata's T test to compare the impact degree of pre-interpreting preparation on various factors of interpretation quality. The results are as follows: 
TABLE III.

INDEPENDENT-SAMPLES T-TeST: THE EFFECT OF PREPARATION BEFORE TRANSLATION ON THE FACTORS OF INTERPRETATION QUALITY

\begin{tabular}{lllllllll}
\hline Source & Test 1 & Test 2 & Mean1 & Mean2 & dif & St_Err & t_value & p_value \\
\hline II by prep: 01 & 36 & 36 & 37.306 & 41.111 & -3.805 & 0.746 & -5.1 & $.000^{* * *}$ \\
T by prep: 0 1 & 36 & 36 & 5.583 & 7.528 & -1.944 & 0.242 & -8.05 & $.000^{* * *}$ \\
Fl by prep: 0 1 & 36 & 36 & 10.528 & 11.389 & -0.861 & 0.297 & -2.9 & $.005^{* * * *}$ \\
LC by prep: 0 1 & 36 & 36 & 7.222 & 8.056 & -0.834 & 0.187 & -4.45 & $.000^{* * *}$ \\
GC by prep: 0 1 & 36 & 36 & 7.139 & 7.778 & -0.639 & 0.175 & -3.65 & $.001^{* * *}$ \\
V by prep: 0 1 & 36 & 36 & 3.611 & 3.861 & -0.25 & 0.109 & -2.3 & $.025^{* * *}$ \\
TS by prep: 0 1 & 36 & 36 & 71.389 & 79.722 & -8.334 & 1.527 & -5.45 & $.000^{* * *}$ \\
\hline
\end{tabular}

$* * * \mathrm{p}<0.01, * * \mathrm{p}<0.05, * \mathrm{p}<0.1$

Note: Test 1 refers to test without pre-interpreting preparation, Test 2 refers to test with pre-interpreting preparation.

From table III, we can see that all $\mathrm{p}$ values in the table are less than 0.05 , indicating that the impact of preparation on the various factors of interpreting quality is significant. Since the scores of various factors of interpreting quality account for different proportion in the total score, when comparing the dif values, it is necessary to divide them by the proportion of each factor in the total score. The relationship between the dif values of the six interpreting factors are as follows: Terminology $>$ Logical Coherence $>$ Information Integrity $>$ Grammatical Correctness $>$ Fluency $>$ Voice. This shows that score on terminology is most affected by preparation, followed by score on Coherence and Information Integrity, while score on voice is least affected.

Afterwards, we conducted paired samples tests on students in the same language level group to see whether preparations had different effects on them.

TABLE IV

PAIRED SAMPLES TESTS: THE IMPACt OF PRE-INTERPRETING PREPARATION ON THE QUALITY OF INTERPRETING OUTPUT WiTHIN THE SAME LANGUAGE LEVEL GROUP

\begin{tabular}{|c|c|c|c|c|}
\hline Variable pair & Mean & SD & $\mathrm{t}$ & Sig.(2-tailed) \\
\hline $\mathrm{A}+\mathrm{N}$ & -7.1944 & 3.2455 & -9.405 & .000 \\
\hline $\mathrm{A}+\mathrm{P}$ & \multirow{3}{*}{-9.4722} & \multirow{3}{*}{4.0383} & \multirow{3}{*}{-9.951} & \multirow{3}{*}{.000} \\
\hline $\mathrm{I}+\mathrm{N}$ & & & & \\
\hline $\mathrm{I}+\mathrm{P}$ & & & & \\
\hline Confidence Interval & & & & \\
\hline
\end{tabular}

Table IV reflects the impact of the pre-interpreting preparation on the quality of interpretation within the same language level group. Among them $\mathrm{A}+\mathrm{P}$ and $\mathrm{I}+\mathrm{P}$ are respectively the base groups in the paired groups. In the $\mathrm{A}+\mathrm{N}$ and $\mathrm{A}+\mathrm{P}$ paired group, the pre-interpreting preparation has a significant effect on the advanced level group $(\mathrm{p}<0.05)$. In the $\mathrm{I}+\mathrm{N}$ and $\mathrm{I}+\mathrm{P}$ paired group, the pre-interpreting preparation also has a significant effect on the intermediate level group $(\mathrm{p}<0.05)$. However, comparing the mean value of the two paired groups, the absolute value of the mean value of the advanced paired group is less than the absolute value of the mean value of the intermediate paired group $(|-7.1944|<|-9.4722|)$, indicating that the pre-interpreting preparation has a greater impact on the intermediate level group.

At the same time, we also adopted paired samples test to observe whether the language level will affect the quality of interpreting output. The results are as follows:

TABLE V.

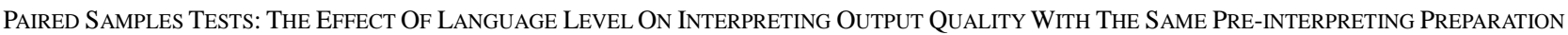

\begin{tabular}{|c|c|c|c|c|}
\hline Variable pair & Mean & SD & $\mathrm{t}$ & Sig. (2-tailed) \\
\hline $\mathrm{P}+\mathrm{A}$ & 9.1667 & 5.1192 & 6.711 & .000 \\
\hline \multicolumn{5}{|l|}{$\mathrm{P}+\mathrm{I}$} \\
\hline $\mathrm{N}+\mathrm{A}$ & 11.444 & 4.668 & 9.634 & .000 \\
\hline \multicolumn{5}{|l|}{$\mathrm{N}+\mathrm{I}$} \\
\hline Confidence Interva & & & & \\
\hline
\end{tabular}

Table $\mathrm{V}$ describes the influence of language level on the overall quality of interpreting output. Among them $\mathrm{P}+\mathrm{A}$ and $\mathrm{N}+\mathrm{A}$ are respectively the base groups in the paired groups. In the $\mathrm{P}+\mathrm{A}$ and $\mathrm{P}+\mathrm{I}$ paired group language level has a 
significant effect on the group with preparation $(\mathrm{p}<0.05)$. In the $\mathrm{N}+\mathrm{A}$ and $\mathrm{N}+\mathrm{I}$ paired group language level also has a significant effect on the group without preparation $(\mathrm{p}<0.05)$. However, the mean value of the group with preparation is less than the mean value of the group without preparation $(9.1667<11.444)$, indicating different language level has different impact on the quality of interpretation output. In other words, pre-interpreting preparation can, to a certain extent, narrow the gap in interpreting output quality brought by language level.

It can be seen from the above analysis that both language level and pre-interpreting preparation affect the interpreting output quality. Therefore, it is necessary to verify whether the pre-interpreting preparation and language level have an interactive effect on interpreting output quality. The results are as follows:

TABLE VI.

MAIn EFFECT AND INTERACTION EFFECT OF THE Two VARIABLES OF PRE-INTERPRETING PREPARATION AND LANGUAGE LEVEL ON THE TOTAL SCORE OF INTERPRETING OUTPUT

\begin{tabular}{ccccc}
\hline Variable source & SS & DF & F & Sig. \\
Main effect & & & 84.767 & .000 \\
PP & 1250 & 1 & 129.638 & .000 \\
LL & 1911.681 & 1 & 1.583 & .213 \\
Interaction effect & & & \\
PP * LL & 23.347 & 1 & & \\
Remaining & 1002.75 & 71 & \\
Total & 4187.778 & & \\
\hline Confidence Interval $(\mathrm{CI})=99 \%$ & Note: PP=Pre-interpreting Preparation, LL=Language Level.
\end{tabular}

Table VI further proves that both pre-interpreting and language level have significant effects on the overall interpretation performance, but the interaction effect is not significant. According to Hatch \& Farhady (1982), in ANOVA, if the interaction effect is not significant, then we can make a stronger and more confident claim on the main effect (Huang Zidong, 1998), which are pre-interpreting preparation (PP) and language level (LL) in this case. Accordingly, Table VI again verifies that pre-interpreting preparation and language proficiency are important for the performance of interpreters, and also confirms the statistical results in Tables IV and V.

\section{DISCUSSION}

\section{A. Pre-interpreting Preparation Effect on the Interpretation Quality}

Our experimental research results show that pre-interpreting preparation has a significant impact on the quality of interpreting output, and there is a positive correlation between the two. According to Gile, CI can be modelled as a process consisting of the four Efforts model, namely "listening and analysis effort", "short-term memory effort", "speech production effort", and "coordination effort" (Gile, 1995, p.149). In order for interpreting to proceed smoothly, the cognitive load of interpreting should be less than the total available processing capacity of the interpreter. Therefore, from the perspective of the interpreter, reducing the cognitive load of each activity in interpreting will help to improve the quality of interpreting output. And full preparation before interpreting provides an effective tool to realize this.

Reducing Listening and Understanding Effort.

There are many factors that affect the interpreters' listening and comprehension, such as the speed of the source speech, the density of information, the length of the segment, terminological expressions, cultural differences, pronunciation of the speaker etc. If the interpreter is fully prepared before interpreting, he or she can effectively reduce the load on listening and understanding. In the second test of our experiment (interpreting with preparation), we prepared four bilingual passages on the subject and 26 relevant terms for the students to prepare. As for how the pre-interpreting preparation facilitates listening and comprehension in the interpreting process, tested student 5 reported this way: "After reading the background material, I feel that the listening is not so strenuous, especially for English-to-Chinese interpreting. The background materials include many keywords of the source speech. These key words can help me to anticipate the next part in listening, which effectively relieves the listening load." Tested student 8 pointed out that "the preparation materials provide professional terminology and related background knowledge. With a better understanding of the terms, I put less efforts on listening and comprehension, leaving more time for target speech production and achieving a better performance in interpreting." From their feedback, it can be seen that pre-interpreting preparation helps to reduce the cognitive load of listening comprehension, so that interpreters can focus more on short-term memory and target speech production to achieve high-quality interpreting output.

Reducing Short-term Memory.

Interpreting activities have extremely high demands on the interpreter's short memory ability. If the interpreter is fully prepared before interpreting, he or she will have a better understanding of the source speech while listening. With a better understanding, the information tends to stay longer in the interpreter's mind, which consequently reduce the load of short-term memory and enables interpreters to allocate more attention to analyze information and organize the 
notes. In return, an orderly and logical note will help interpreters better recall the speech segment just heard. As a result, the integrity and logic of the interpreting output will be improved. Test student No.34 mentioned in her post-interpreting $\log$ that "pre-interpreting preparation made me more attentive in the interpreting process. Compared with my first test (interpreting without preparation), the notes are more concise, because with a better understanding, I needn't write down every word of the long sentences. The efficiency of taking notes was raised a lot."

\section{Reducing Speech Production Load.}

According to Gile's definition of the two phrases of the CI process, the speech production is based on the listening comprehension, note-taking, short-term memory and coordination. As mentioned above, adequate pre-interpreting preparation can effectively improve the interpreter's listening comprehension, optimize the effect of notes, and strengthen short-term memory, thereby reduce the interpreter's cognitive load in these aspects, and allocate more attention to the output of the target speech. The interpreter will have more time to consider the lexical choice, the syntactical structure of the sentence, and the logic of the target language speech. Tested student No.11 reported that "understanding the background knowledge before interpreting will better activate the related vocabulary in the process of producing the target speech and the sentences are more coherent."

\section{Reducing Coordination Load.}

Gile (1995) pointed out that "coordination" refers to the interpreters' mental operation of managing his/her processing capacity, specifically assigning the right amount of attention to the activities involved in interpreting. Coordination itself is also a load, consuming interpreters' attention. During the interpreting process, if the interpreter is too stressed, it will inevitably affect the interpreter's attention distribution. Adequate pre-interpreting preparation can reduce the psychological burden on interpreters and boost their confidence. Especially when they encounter difficulties in interpreting, a well-prepared interpreter is more likely to maintain calmness and distribute their attention reasonably, which helps the interpreters to play their best. In our experiments, we conducted a questionnaire survey on the interpreter's state of mind right before interpreting test. According to the data, for test 1 (without pre-interpreting preparation), $92 \%$ of the tested students were nervous and $3 \%$ were very nervous, while for test 2 (with pre-interpreting preparation) only $30 \%$ of the students tested were nervous, and $50 \%$ were a little nervous. The above survey results indicate that preparation before interpreting can effectively reduce the psychological pressure on interpreters. According to the post-interpreting feedback, more than half of the participants mentioned the positive impact of the pressure relief on the quality of interpreting output. Tested student No.18 said, "Because of the lack of knowledge in the financial area, without any preparation, I was very anxious in the interpreting process. My mind went blank twice when producing target language speech. I had difficulty in recalling what I have just heard, even though I was pretty sure I understood the source speech segment while listening." Test student number 26 reflected that "without preparation, many terms were new to me. Every time I heard those new terms, I got stuck and directed most of my attention on them, which resulted in the loss of the whole sentence."

\section{B. Pre-interpreting Preparation Effect on Various Quality Factors}

Judging from the experimental data, the pre-interpreting preparation has a relatively large degree of impact on the terminology and logic coherence of the target speech, and the least impact on the voice quality.

As far as professional terminology is concerned, this might be related to the features of business English interpretation. Business speech contains a large number of business English terms. Take the interpreting materials in the experiment as an example, Part I and part II contain altogether 30 financial terms. These terms are highly specialized and increase the difficulty of interpreting. However, the accuracy of terms is very important to the quality interpreting output. Due to the immediacy of interpreting, interpreters have no time to consult the data to confirm the interpretation of terms. Therefore, preparation of professional terminology before interpreting will effectively improve the accuracy of professional terminology. For example, in this experiment, both Part I and Part II of the test material include the term "inter-bank lending market". Without preparation, only $8 \%$ of students interpreted this term accurately. Then, we include this term in our term list for the tested students to prepare before test 2 starts. In the test 2 , the accuracy of the term reached $97 \%$. The tested student No.22 recorded his experiences in the post-interpreting log: "For unprepared interpreting, professional terminology is the most difficult point for me. The loss of one professional terminology will lead to the loss of the entire sentence. With preparation, my interpretation of the terms is more accurate." Tested student No.36 reported that "To me, the greatest benefits of preparation before interpreting is to solve terminology problems and reduce most of my uncertainty in interpreting process."

As far as the logical coherence of the interpreting output is concerned, in the process of interpreting, the interpreter needs to take logical analysis in processing the information heard and producing a logical target language speech. For example, when taking notes, if the notes are clear in logic and highly structured, it can reduce the burden of information processing and help to improve the logic coherence of the interpretation output. In the speech production phrase, prepared interpreters will have more attention to adjust the syntactic structure, integrate the logic analysis into language conversion, remove the redundant information, and add logical connectors. thus, the prepared interpreter will effectively improve the logical coherence of the interpreting output. Tested student No.12 reported that "Without preparation, my notes are messy, which can hardly be recognized and understood by myself. After an adequate preparation, my notes are more organized and recognizable. And the logical relationship between sentences is easier to identify."

Voice quality in our study mainly includes pronunciation, intonation, and interpreters' control over voice. Data 
shows that pre-interpreting preparation has the least effect on it. That's mainly because the pronunciation and intonation of an interpreter are developed in long term, which are impossible to be enhanced during short period of time. However, the study found that pre-interpreting preparation helps interpreters to improve their control over the voice. Grader 1 mentioned in the interview that "when grading the interpreting work in Test 1 (unprepared interpreting test), I noticed that the voices of a few students were trembling slightly, probably because of nervousness. For the second test (prepared interpreting test), there was basically no such situation." Student No.19 reported that "When I did the first interpreting (unprepared interpreting), my voice became weaker and weaker when encountering long sentences. With an adequate preparation, this situation rarely occurred in the second interpreting." In general, pre-interpreting preparation has relatively small effect on the interpreter's pronunciation and intonation, but it can help the interpreter reduce the pressure, enhance the interpreter's confidence and strengthen their control of the voice.

\section{The Change of Pre-interpreting Preparation Effect with Different Language Levels}

In order to study this question, we divided the tested students into advanced level group and intermediate level group according to their language ability. Experimental data shows that preparation before interpreting has a greater impact on the interpreting output of the intermediate level group than that of the advanced level group.

Advanced level students are better at associating and anticipating in the interpreting process. In the case of unprepared interpreting, when they miss certain word or phrase, they can possibly add the information based on their understanding. Therefore, the target language speech is relatively complete, and there will be much less interpreting jam because of an unknown term or a difficult word. However, in the same situation, students at intermediate level are more likely to lose the entire sentence. In the case of interpreting with preparation, students of both groups are fully prepared with background knowledge and key terms. For intermediate level students, the possibility of missing the key information will be reduced dramatically. As a result, the completeness and fluency of the interpreting output will be much better than those without preparation. At the same time, compared with the unprepared interpreting, the change of advanced level students' performance is relatively small. However, we also found that even though the intermediate level students improved their interpreting output to a greater extent with the help of pre-interpreting preparation, their interpreting output in Test 2 is still not as good as that of the high level of students. That is to say, short-term preparation before interpreting can improve the quality of interpreting, but students still need to constantly enrich their language knowledge and improve their language ability, so as to achieve high-quality interpreting output.

\section{Implications to the Teaching of Business Interpreting}

This study has some important implications for business interpreting teaching. First of all, it is not enough to teach students interpreting skills only in business interpreting class. Business interpreting involves multiple fields of business, such as human resources, logistics, marketing, insurance, finance, etc. These business fields are highly professional and have many professional terms. Therefore, teachers should pay attention to the input of business knowledge and guide students to accumulate business professional terminology. Since students learn business terminology mainly from native-language materials, teachers should guide students to use these terms correctly in interpreting.

Secondly, business interpreting teachers should focus on cultivating students' habit of preparation before interpreting. Business interpreting courses are often based on business topics. Before studying each unit, teachers can require students to prepare for the interpreting independently in the aspects of the background knowledge, professional terminology, speaker, and interpreting environment, so as to help students form the habit of pre-interpreting preparation. Gradually, what students learned in each short-term preparation will become long-term memory, which will surely bring about positive effect to the interpreting output.

Thirdly, the experimental results show that students' bilingual ability is one of the key factors affecting students' interpreting. Therefore, teachers should focus on improving students' bilingual competence in teaching, particularly their English listening and speaking.

\section{CONCLUSION}

This study explores the impact of pre-interpreting preparation on interpreting quality. Based on the analysis, the following conclusions are reached. Firstly, pre-interpreting preparation has a positive effect on the overall quality of business interpreting output. Secondly, in business scenarios, pre-interpreting preparation have different degrees of impact on the factors of interpretation quality. Specifically, it has a relatively large impact on the accuracy of terminology and the logical coherence of the target-language speech, while exerting a minimal impact on the voice quality factor. Thirdly, pre-interpreting preparation has a greater influence on the interpreting output of the intermediate language level group than it has on that of the advanced language level group.

In this study, we designed an experiment to conduct an empirical research on business interpreting. Altogether, 36 English majors from the same Chinese university participated in the experiment. The size needs to be expanded. And the single background of the participants could also be thought as one limitation of the study. In the future, in order to provide more convincing results and applicable suggestions on the preparation for business interpreting, we will further the study by including more participants with diverse educational backgrounds. 


\section{REFERENCES}

[1] Andrew, G. (2005). Note-taking in Consecutive Interpreting. Manchester: St. Jerome Publishing Co.

[2] Chen Mingyao. (2004). Basic Techniques of Business Interpretation. Shanghai Journal of Translators for Science and Technology, (02):31-34.

[3] Fantinuoli, C. (2017). Computer-assisted preparation in conference interpreting. The International Journal for Translation \& Interpreting Research, 9(2):24-37.

[4] Gerver, D. (1976). Empirical studies of simultaneous interpretation: A review and a model. Brislin R Translation: Applications and Research, (23):165-207.

[5] Gao Weihong, Li Jincong. (2013). The Enlightenment of Gill's Interpretation Model on Improving the Ability of Business Interpreters. China-Today Forum, (Z1):176-177.

[6] Gile, D. (1999). Testing the Effort Models' Tightrope Hypothesis in Simultaneous Interpreting - A Contribution. Journal of Linguistics, (23):154-155.

[7] Gile, D. (1992). Predictable sentence endings in Japanese and conference interpretation. The Interpreters' Newsletter, Special Issue (1):12-23.

[8] Gile, D. (1995). Basic Concepts and Models for Interpreter and Translator Training. Amsterdam: John Benjamins Publishing Co.

[9] Gile, D. (1991). Methodological Aspects of Interpretation (and Translation) Research. Target, (2):153-174.

[10] Hiroko Yamada. (2019). A Direct Application of Simultaneous Interpreting Training without Prior Consecutive Interpreting Work in a University Course. Theory and Practice in Language Studies, (09):353-363.

[11] Huang Zidong. (1998). The Effects of Topic Familiarity, Proficiency Level and Question Type on EFL listening comprehension: ST and RT Perspectives. Modern Foreign Languages, (04):3-5.

[12] Lambert, S. (1994). Simultaneous interpretation: One ear may be better than two. Bridging the Gap: Empirical Research in Simultaneous Interpretation. Amsterdam /Philadelphia: John Benjamins Publishing Co.

[13] Li Wei. (2009). Preparation before Interpreting and Its Influence on the Working Memory. Fujian Foreign Languages and Literature Association: Fujian Foreign Languages and Literature Association, 594-602.

[14] Li Yu, Zhang Yong. (2005). A New Probe into the Teaching and Examination Reform of Interpretation Courses for Business English Majors. Foreign Language World, (03):32-36+42.

[15] Liu Heping. (2001). Interpreting Skills: Approaches to Teaching Interpretation. Beijing: China Translation \& Publishing Corporation.

[16] Liu Heping. (2002). Translation for Science \& Technology and Assessment. Shanghai: Shanghai Journal of Translators for Science and Technology, (1):33-37.

[17] Liu Heping. (2007). Preparation before translation and quality of interpretation. Journal of Language and Literature Studies, (07):73-76.

[18] Liu Xuehui. (2006). Planning of Oral Interpretation Technology. Journal of Beijing International Studies University, (06):88-91.

[19] Moser, B. (1978). Simultaneous interpretation: a hypothetical model and its practical application. Language Interpretation and Communication, (18):353-368.

[20] Kurz, I. (2001). Conference Interpreting: Quality in the Ears of the User. Meta, (2):394-409.

[21] Kurz, I. (2002). Conference Interpretation: Expectations of Different User Groups. In Ptichhaeker and Schlesinger (eds.) The Interpreting Studies Reader. London and New York: Routledge.

[22] Seleskovitch, D. (1962). L'Interprétation des Conferences. Babel,8/1.

[23] Seleskovitch, D. (1978). Language and Cognition. In Gerver, D. and Sinaiko. H. W. (eds.). Language and Communication. New York: Springer. 333-342.

[24] Seleskovitch, D. (1978). Interpreting for International Conferences: Problems of Language and Communication. Trans. D. Stephanie \& E. N. Mc Millan. Washington: Pen and Booth.

[25] Seleskovitch. D. \& Lederer M. (1995). A Systematic Approach to Teaching Interpretation. Translated by J. Harmer. Luxembourg: Official for Publications.

[26] Stoll, C. (2009). Jenseits simultanfähiger Terminologiesysteme. Trier: Wvt Wissenschaftlicher Verlag.

[27] Sun Mu. (2017). Preparation in Consecutive Interpretation on the Basis of Effort Model---A case study of the Interpretation on the Basis of Effort Model. Beijing: University of International Business and Economics.

[28] Wang Jinbo, Wang Yan. (2006). Features of Interpreting and Interpreting Teaching Materials. Foreign Language World, (05):41-47.

[29] Xu Ran. (2018). Construction of pre-interpreting preparation model based on corpus technology. Chinese Translators Journal, 39(03):53-59.

[30] Zhang Jiliang. (2003). Interpreting Preparation in Interpreting Context Strategies Problems. Chinese Science \& Technology Translators Journal, (03):13-17.

[31] Zhang Wie \& Ke Fei. (2008). The Effect of Interpreting Users in Interpreting Assessment. Foreign Language Research, (03) $114-118$

[32] Zhong Huimin. (2016). Experimental Research on the Influence of Subject Familiarity on Interpretation Quality. Foreign Language and Translation, 23(02):63-70.

[33] Zhong Weihe. (2018). A Foundation Coursebook of Interpreting Between English and Chinese. Beijing: Higher Education Press. 
Xiaoli Song is a lecturer at North China Electric Power University. She holds a master's degree in cross-cultural communication from University of International Business and Economics (Beijing). Her main research interests include business interpreting, business communication across cultures.

Mingzhu Tang obtains a bachelor's degree from North China Electric Power University and is studying for a master's degree in cross-cultural communication in University of International Business and Economics. Her research interest lies in translation, second language acquisition, and cross-cultural communication. 